\title{
Statistics Analysis Measures Painting of Cooling Tower
}

\author{
A. Zacharopoulou, E. Zacharopoulou, and G. Batis \\ Department of Materials Science and Engineering, School of Chemical Engineering, National Technical University of Athens, \\ 9 Heroon Polytechniou, Zografou, 15771 Athens, Greece \\ Correspondence should be addressed to A. Zacharopoulou; aggeliki.zaxaropoulou@gmail.com
}

Received 30 April 2013; Revised 26 August 2013; Accepted 14 October 2013

Academic Editor: Vagelis G. Papadakis

Copyright (C) 2013 A. Zacharopoulou et al. This is an open access article distributed under the Creative Commons Attribution License, which permits unrestricted use, distribution, and reproduction in any medium, provided the original work is properly cited.

\begin{abstract}
This study refers to the cooling tower of Megalopolis (construction 1975) and protection from corrosive environment. The maintenance of the cooling tower took place in 2008. The cooling tower was badly damaged from corrosion of reinforcement. The parabolic cooling towers (factory of electrical power) are a typical example of construction, which has a special aggressive environment. The protection of cooling towers is usually achieved through organic coatings. Because of the different environmental impacts on the internal and external side of the cooling tower, a different system of paint application is required. The present study refers to the damages caused by corrosion process. The corrosive environments, the application of this painting, the quality control process, the measures and statistics analysis, and the results were discussed in this study. In the process of quality control the following measurements were taken into consideration: (1) examination of the adhesion with the cross-cut test, (2) examination of the film thickness, and (3) controlling of the pull-off resistance for concrete substrates and paintings. Finally, this study refers to the correlations of measurements, analysis of failures in relation to the quality of repair, and rehabilitation of the cooling tower. Also this study made a first attempt to apply the specific corrosion inhibitors in such a large structure.
\end{abstract}

\section{Introduction}

Generally the concrete comprises a protective environment of the reinforcement for the two reasons following.

(i) The aqueous solution of the pores of the reinforcement is intensely alkaline due to lime, which is the product of reaction of the cement hardening, its $\mathrm{pH}$ between 12.5 and 13.9. Under these circumstances, steel is superficially covered by a passive layer of iron oxides, which impedes its corrosion. Steel corrosion is restrictive to the maintenance of this passive layer; an action is so slow that it could practically be ignored.

(ii) The concrete acts as a natural barrier between the reinforcement and the various corrosive elements of the environment (such as oxygen and carbon dioxide) as well as other substances which may induce corrosion (such as chlorides).

In time, cement may lose its protective capacity, for example, due to carbonation which is the reaction of carbon dioxide with calcium hydroxide. Then the $\mathrm{pH}$ may reach scales lower than 9, so the steel passes from the passive into the active state. Another reason for the corrosion of the reinforcement is the existence of chlorides. Chlorides penetrate the passive layer of oxides and cause corrosion in the form of acupuncture. The type of steel bars is S500s. The concrete coverage of rebar is $30 \mathrm{~mm}$.

The corrosion of the reinforcement into the concrete with $\mathrm{pH}$ lower than 9 is an electrochemical action, which takes place when three prerequisites are fulfilled:

(i) anodic dissolution of iron,

(ii) existence of oxygen,

(iii) electric conductivity through the pores of the cement.

The speed of this action is highly dependent on the environmental conditions. It is quite slow in the case of the existence of the passive layer. However, it increases significantly when the $\mathrm{pH}$ value falls under 9. The same happens when the passive layer is destroyed by a sufficient amount of chlorides.

Cooling towers are made of reinforced concrete. The reinforcement is like two nets, an interior, and an exterior 


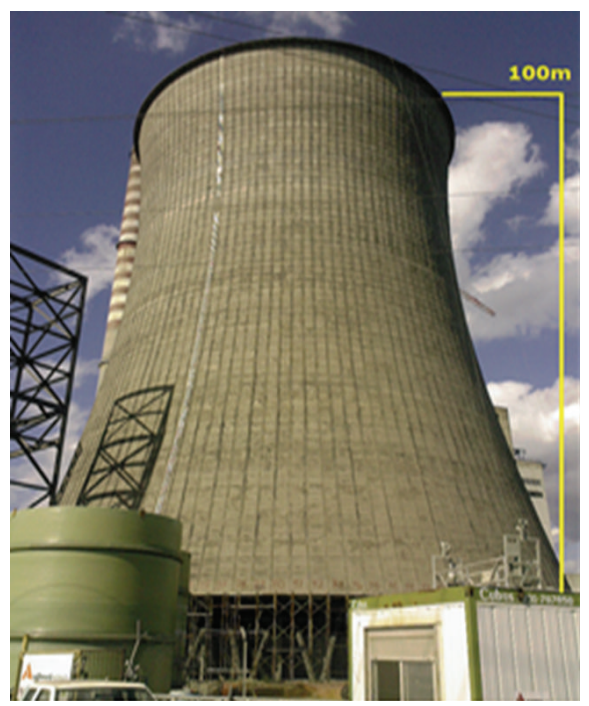

FIgURE 1: Cooling tower unit III of Megalopolis.

one. Vertical reinforcements are placed on both the inner and the outer surface, towards the interior of the concrete while the horizontal ones are towards the exterior of concrete. As a consequence, vertical reinforcements are better protected against corrosion than the horizontal $[1,2]$.

The corrosive environment on the inner side differs from the one on the outer $[3,4]$. In the inside, the warm water introduced from the whirls of the production of electric current is inducted and then it is sprayed into plastic or wooden midriffs through a network of pipes. In this way, the water is evenly dispersed within the tower and part of it evaporates while the rest of it is cooled. The cool water is collected in the tank at the base of the cooling tower and then it is recycled. It is believed that inside the cooling tower (up to one particular height) there is only vapor and very little oxygen. The existence of oxygen into a higher point, through is significant. The vapor gets away from the top of the tower. On the inside surface of the tower a water membrane is formed. A portion of water from the inside of the cooling tower goes through the concrete and evaporates on the outer surface.

The transfer of water creates the conductive environment which favors the corrosion of reinforcement in concrete. On the outside surface the influence of carbon dioxide is strong, because around the cooling tower was the chimney of turbines factory, which reduces the $\mathrm{pH}$ and oxygen and promotes creates of the oxides. Additionally it is mentioned that there are four additional power plants in the region around the cooling tower. Through this analysis, we conclude that on the outside surface of the tower signs of corrosion of the reinforcement are more likely to occur [5]. The inspection of the cooling tower verifies this theoretical picture (Figure 1).

The minimum and the maximum loss of existing reinforced section were from $0 \%$ to $70 \%$. The use of cooling towers water to retain the sulfur oxide from the exhaust-gases changed the $\mathrm{pH}$ of water from neutral into acid. For this reason the protection of cooling towers must be strengthened.

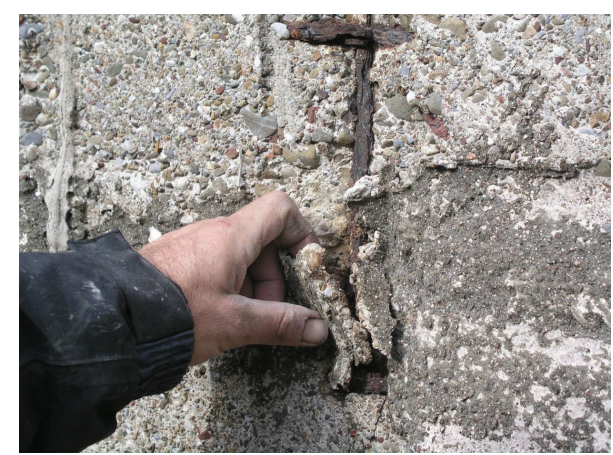

FIGURE 2: Ablation of concrete, before maintenance.

There were cases, as in Figure 2 (thickness carbonation was $36 \mathrm{~mm}$ ), that the depth of carbonation has overcome the concrete coverage.

\section{Corrosion and Deterioration of the Cooling Tower}

Due to both operational and environmental conditions, the towers are liable to malfunctions because of the corrosion of the reinforcement. The cooling towers show many problems of corrosion of the reinforcement (Figure 2). In this particular case, on the outside surface, in many places the reinforcement had been corroded and the cover of concrete was removed. At various points, the corrosion of reinforcement has reduced the diameter of rebar; therefore, the reinforcement must be cut and restored with new section of reinforcement. In this particular case, much attention was paid to the protection of reinforcements against corrosion and against carbonation in order to repair the tower [6, 7]. The applied method of protection against corrosion was the use of organic coatings. The requirements for the painting systems are explained in the instruction VGB "R 612 Ue" [8] (Protection Measures on Reinforced Concrete Cooling Towers and Chimneys against Operational and Environmental Impacts). Please note that the repair study was completed before application of EN1504.

The method of repair provided the following.

(i) Removal of the covered parts of concrete to such an extent as to gain relevance of $1.5 \mathrm{MPa}$. In particular for the concrete of the inside surface of the cooling tower has to be the layer of organic deposits, which had been formed removed.

(ii) Cleaning of corroded reinforcement from corrosion products mechanically. Replacement reinforcement, which is necessary.

(iii) Coating of reinforcement with cementitious coatings.

(iv) Rehabilitation of concrete repair mortar.

(v) Protection of the cooling tower with an organic system coating on the surface of concrete.

The purpose of the use of organic coatings is as follows.

(i) To prevent as much as possible the intrusion of water from the inside surface of the tower. 


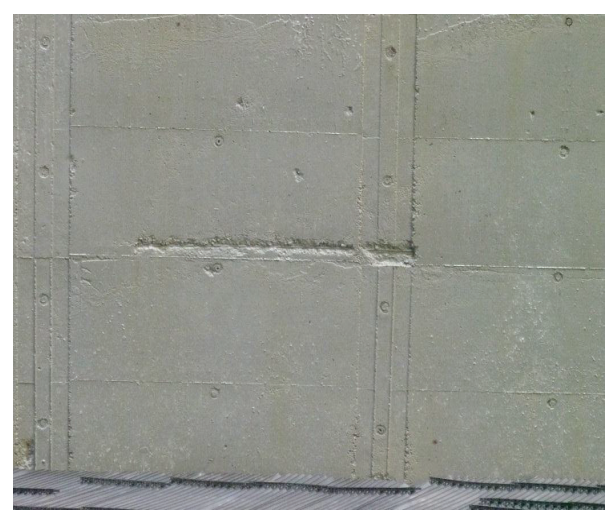

Figure 3: Concrete after maintenance.

(ii) To help the outlet of the vapor on the outside surface, while at the same time reduce the inlet of oxygen and carbon dioxide.

(iii) In the case when the cooling tower is used to retain the waste-gases, the organic coating on the inside surface of the tower must be capable of enduring the acidity of the water.

The system of organic coatings for the outside surface of the cooling tower was

(1) hydrophobic primer,

(2) two layers of acrylic emulsion of total thickness $200 \mu \mathrm{m}$.

The system of organic coatings for the inside surface of the cooling tower was

(1) epoxy primer,

(2) two layers of epoxy coating of total thickness $300 \mu \mathrm{m}$ (system 1),

(3) for the part of the interior of CT, existing solar radiation (above the ring) was covered with polyurethane $150 \mu \mathrm{m}$ (system 2).

The final figure of the surface of the concrete after repair is shown in Figure 3.

\section{Measurement Methods}

3.1. Controlling of the Pull-Off Test. Purpose of this method is to estimate the relevance of repair mortal concrete to the painting and to estimate the relevance of old concrete to the painting. According to BSEN 24624 (93) and ISO 4624 (1978) (Figure 4).

3.1.1. Acceptance Measures. The testing of the pulloff was acceptable when the measures were better than $\beta_{\mathrm{HZ}}=$ $1.5 \mathrm{~N} / \mathrm{mm}^{2}$. This value was chosen according to VGB " $\mathrm{R} 612$ Ue."

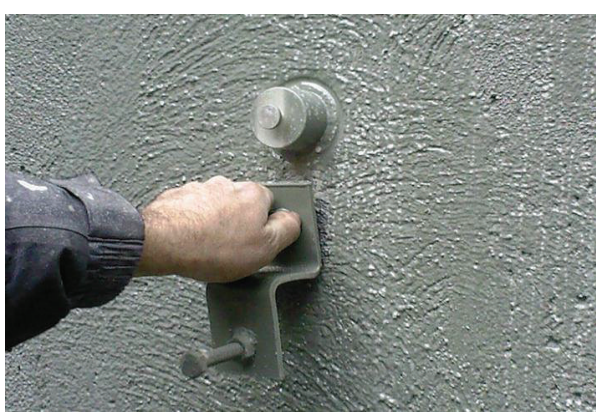

Figure 4: Pull-off test.

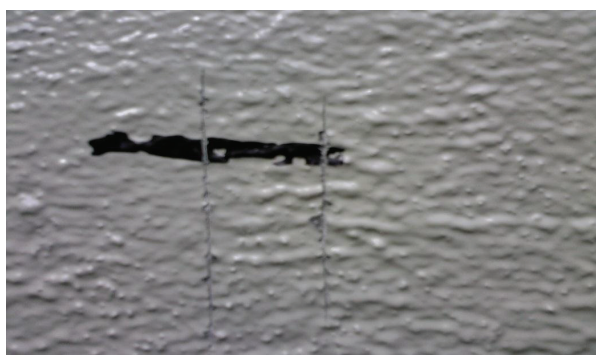

FIGURE 5: Cut test: measuring of the film thickness.

3.2. Examination of the Adhesion with the Cross-Cut Test. Purpose of this method is to estimate the adhesion of organic coating on the substrate and also between the primer and the second coating layer or between different coating layers or the cohesive strength of some substrates, according to ISO $2409 \mathrm{~N}: 1992(\mathrm{E})$. The test is performed at temperature $(23 \pm 2)^{\circ} \mathrm{C}$, with special engraver made on the surface of the coating initially 6 horizontal alignments $(20-30 \mathrm{~mm})$ and then perpendicular to the previous 6 to form a lattice. All scratches must penetrate the surface of the substrate in accordance with the requirement of the standard. The test is performed at 3 different points; on the selected surface, where the 3 scores differ by more than one classification unit, the test should be repeated in another 3 points. The acceptance tests are the categories 0 and 1 .

3.3. Measuring of the Film Thickness. The examination of the film thickness of the relevant surface protection coating shall be done with the wedge-cut test according to DIN 50986 [9]. Purpose of this method is to estimate the film thickness of concrete and also the film thickness of reinforcement (Figure 5).

3.3.1. Acceptance Measures. The minimum film thickness for reinforcement was acceptable: $S_{\min }=1000 \mu \mathrm{m}$.

The minimum film thickness for concrete was acceptable: $S_{\text {min }}=300 \mu \mathrm{m}$ for system 1 and $S_{\text {min }}=150 \mu \mathrm{m}$ for system 2 .

Due to time constraints the project owner accepted that some areas of the cooling tower are to be recoated without measuring. 


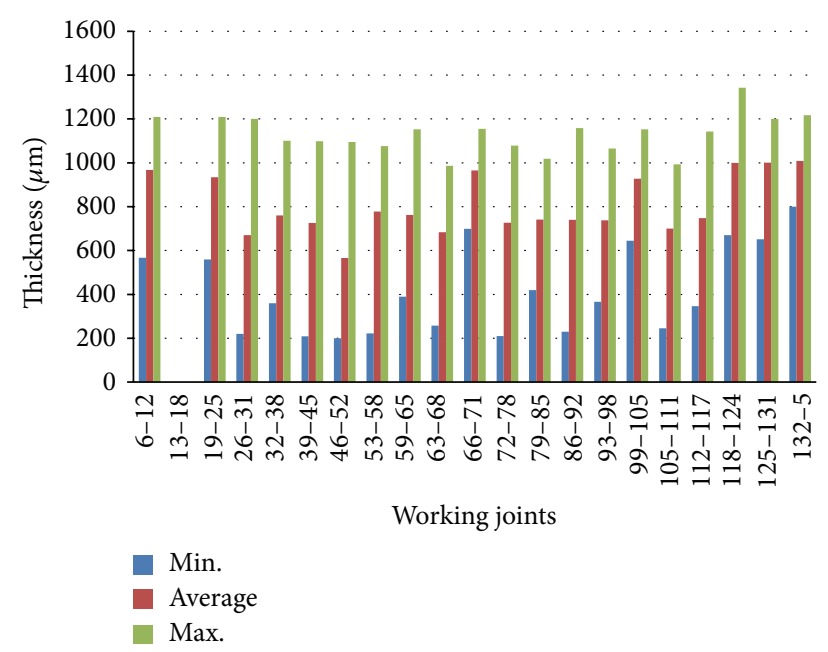

FIGURE 6: Thickness corrosion protection of rebar with cementitious coating for external shell.

TABLE 1: Measurements of pull-off test for external and internal shell.

\begin{tabular}{lccc}
\hline $\begin{array}{c}\text { External shell } \\
\text { Pull-off test }\end{array}$ & MPa & $\begin{array}{c}\text { Internal shell } \\
\text { Pull-off test }\end{array}$ & MPa \\
\hline 1 & 3.1 & 1 & 3 \\
2 & 3.9 & 2 & 3.5 \\
3 & 2.1 & 3 & 2.8 \\
4 & 2.4 & 4 & 3.2 \\
5 & 2.4 & 5 & 2.7 \\
6 & 1.6 & 6 & 1.8 \\
\hline
\end{tabular}

\section{Experimental Part}

The repair process begins with the removal of loose sections in order to achieve concrete strength above $1.5 \mathrm{MPa}$. Table 1 shows the measurements of relevance that link the concrete with painting. Following the requirements of the study, the following measurements were obtained. All the values of the measurements are higher than the critical value of $1.5 \mathrm{MPa}$.

Then the removal of damaged reinforcement and the replacement with new reinforcement took place. Afterwards, the reinforcements are covered with cementitious coating.

Figure 6 shows the averages of measurements of the thickness of cementitious coating of reinforcement on the outside of the cooling tower. The axis $X$ showed the separation areas of cooling tower. The average of measurements was not $1000 \mu \mathrm{m}$ (according to the convention) but $850 \mu \mathrm{m}$.

Figure 7 shows the standard deviation of cementitious coating of reinforcement which was almost $195.23 \mu \mathrm{m}$ in all working joints. The axis $X$ showed the separation areas of cooling tower.

It should be noted that we faced certain difficulties when measuring the coating thickness of reinforcement:

(1) the surface of reinforcement is uneven. The height of nerves of reinforcement is $150 \mu \mathrm{m}$;

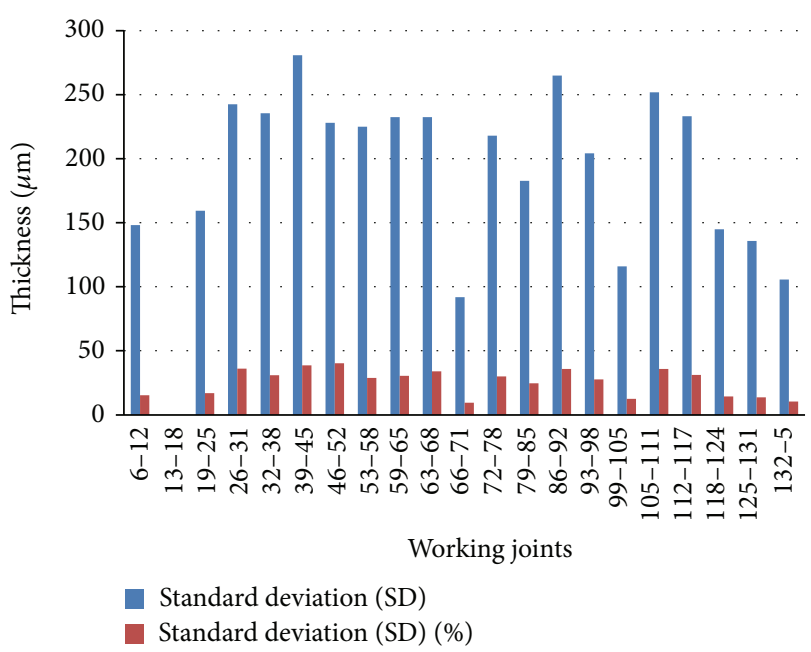

FIGURE 7: Standard deviation of reinforcement of external shell.

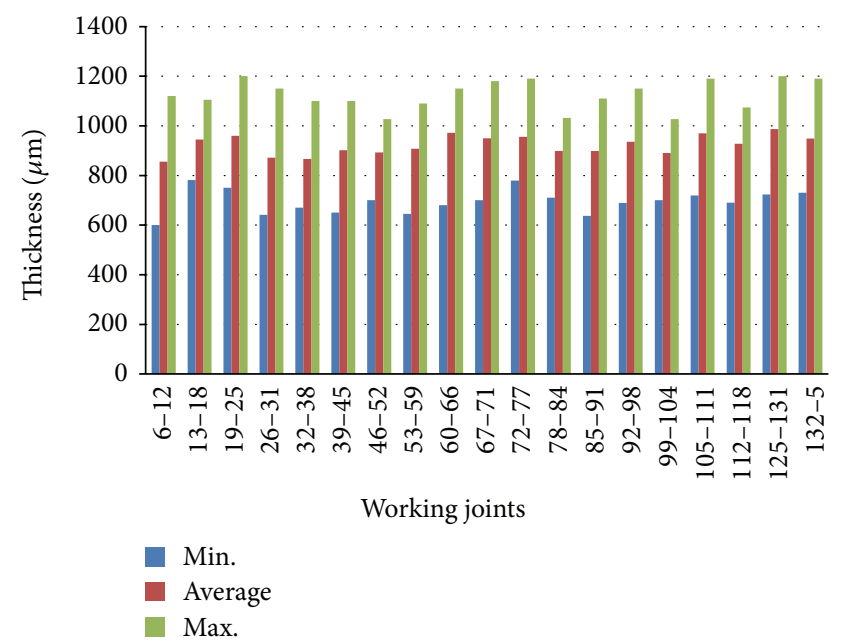

FIGURE 8: Thickness protection coating of reinforcements $(\mu \mathrm{m})$ for internal shell.

(2) the back side of reinforcements (to concrete) is not suitable for uniform coating;

(3) the weather has an influence in the quality of work.

From the above measurements we come to the conclusion that the difference between maximum and minimum value is $650 \mu \mathrm{m}$. The overall distribution of coating thickness follows the normal distribution.

Analytical measurements of Figures 6 and 7 are presented in Table 2 .

Figure 8 shows the average measurements of the thickness of the anticorrosion coating of reinforcement on the inside of the cooling tower. It should be noted that the reinforcements, in general, were not covered with mortar repair. For the reinforcements above the ring of the cooling tower, the thickness of organic coatings had to be $950 \mu \mathrm{m}$ (the thickness of cementitious coating $500 \mu \mathrm{m}$, the epoxy paint of concrete $300 \mu \mathrm{m}$, and polyurethane $150 \mu \mathrm{m}$ ). For the reinforcements under the ring of the cooling tower the 
TABLE 2: Thickness protection coating in $\mu \mathrm{m}$ of reinforcement for external shell.

\begin{tabular}{|c|c|c|c|c|c|}
\hline \multicolumn{6}{|c|}{ Thickness corrosion protection reinforcement for external shell. } \\
\hline Working joints & Average & Min. & Max. & $\begin{array}{c}\text { Standard deviation } \\
\text { (SD) }\end{array}$ & $\begin{array}{c}\text { Standard deviation (SD) } \\
(\%)\end{array}$ \\
\hline $6-12$ & 967.24 & 567 & 1209 & 148.15 & 15.32 \\
\hline $13-18$ & 0 & 0 & 0 & 0 & 0 \\
\hline $19-25$ & 934.56 & 559 & 1209 & 159.40 & 17.06 \\
\hline $26-31$ & 670.48 & 220 & 1200 & 242.49 & 36.17 \\
\hline $32-38$ & 760.36 & 360 & 1100 & 235.47 & 30.97 \\
\hline $39-45$ & 725.41 & 209 & 1098 & 280.84 & 38.72 \\
\hline $46-52$ & 566.38 & 200 & 1095 & 228.05 & 40.26 \\
\hline $53-58$ & 778.09 & 222 & 1076 & 224.91 & 28.91 \\
\hline $59-65$ & 761.93 & 390 & 1153 & 232.38 & 30.50 \\
\hline $63-68$ & 683.32 & 258 & 986 & 232.34 & 34.00 \\
\hline $66-71$ & 964.65 & 699 & 1155 & 91.83 & 9.52 \\
\hline $72-78$ & 726.48 & 210 & 1078 & 217.90 & 29.99 \\
\hline $79-85$ & 740.64 & 420 & 1018 & 182.60 & 24.66 \\
\hline $86-92$ & 740.05 & 230 & 1158 & 264.87 & 35.79 \\
\hline 93-98 & 737.73 & 366 & 1065 & 204.17 & 27.68 \\
\hline 99-105 & 927.00 & 645 & 1153 & 116.03 & 12.52 \\
\hline 105-111 & 699.55 & 245 & 993 & 251.71 & 35.98 \\
\hline $112-117$ & 747.37 & 346 & 1143 & 233.17 & 31.20 \\
\hline $118-124$ & 999.21 & 670 & 1342 & 144.84 & 14.50 \\
\hline $125-131$ & $1,000.05$ & 651 & 1200 & 135.89 & 13.59 \\
\hline $132-5$ & $1,008.76$ & 800 & 1217 & 105.78 & 10.49 \\
\hline
\end{tabular}

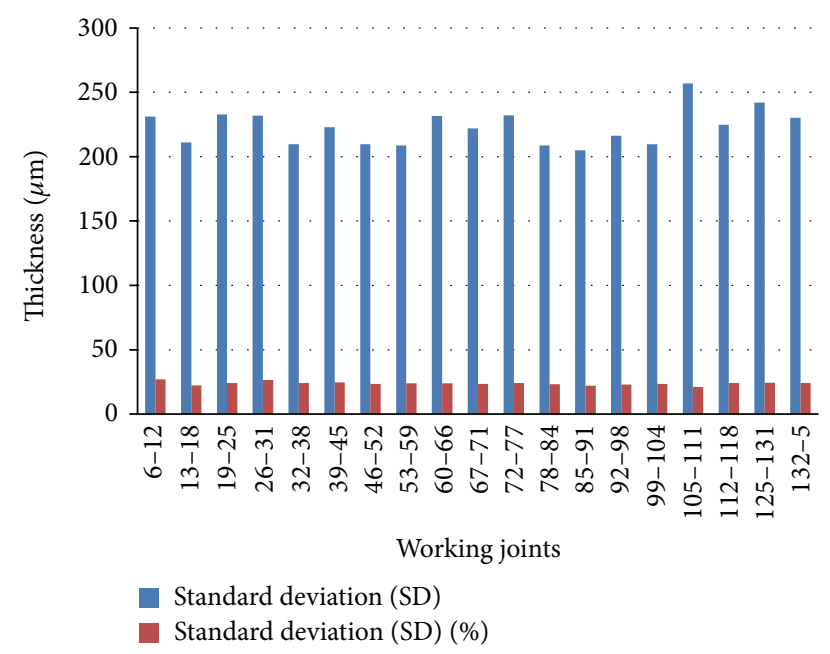

FIgURE 9: Standard deviation of the total thickness coatings to concrete surface of the internal shell.

thickness of paint had to be $800 \mu \mathrm{m}$. The average of values amounts to $875 \mu \mathrm{m}$. After applying the cement coating of reinforcement, it was followed by the application of mortar repair. After the restoration of concrete organic coatings were applied.

Cementitious coating thickness of cooling tower reinforcements must be the same whether the reinforcement was located inside or outside of the cooling tower.
Figure 9 shows the standard deviation of measurements of the thickness of the anticorrosion coating of reinforcement on the inside of the cooling tower which was almost $223 \mu \mathrm{m}$ in all working joints. The axis $X$ showed the separation areas of cooling tower. Analytical measurements of Figures 8 and 9 are presented in Table 3.

The relevance of organic coatings of concrete was tested with the cross-cut method. The measurements are shown in Figure 15 according to the ISO 2409N [10].

The acceptance tests are the categories 0 and 1 :

category 0: none of the squares of the panel are detached:

category 1: detachment of small flakes of coating on the prices of the lines affected an area of the panel not more than $5 \%$.

Figure 10 shows the total coating thickness of acrylic coating on the outside of cooling tower. The thickness of the acrylic coating should be $200 \mu \mathrm{m}$. According to Figure 10, all measurements were greater than the limit $(200 \mu \mathrm{m})$.

Figure 11 shows the standard deviation and the standard deviation\% of measurements of the coating outside of the cooling tower. The average standard deviation was almost $12.1 \mu \mathrm{m}$ in all working joints. It is remarkable that the painting of concrete is simpler than the painting of reinforcement. Analytical measurements of Figures 10 and 11 are presented in Table 5. 
TABLE 3: Thickness corrosion protection in $\mu \mathrm{m}$ of reinforcement for internal shell.

\begin{tabular}{|c|c|c|c|c|c|}
\hline \multicolumn{6}{|c|}{ Thickness corrosion protection reinforcement for external shell. } \\
\hline Working joints & Average & Min. & Max. & $\begin{array}{c}\text { Standard deviation } \\
\text { (SD) }\end{array}$ & $\begin{array}{c}\text { Standard deviation (SD) } \\
(\%)\end{array}$ \\
\hline $6-12$ & 856.05 & 600 & 1120 & 231.12 & 27.00 \\
\hline $13-18$ & 945.23 & 782 & 1105 & 210.95 & 22.32 \\
\hline $19-25$ & 959.73 & 750 & 1200 & 232.70 & 24.25 \\
\hline $26-31$ & 871.73 & 641 & 1150 & 231.91 & 26.60 \\
\hline $32-38$ & 866.68 & 670 & 1100 & 209.64 & 24.19 \\
\hline $39-45$ & 902.00 & 650 & 1100 & 222.97 & 24.72 \\
\hline $46-52$ & 892.52 & 700 & 1027 & 209.75 & 23.50 \\
\hline $53-59$ & 908.00 & 645 & 1090 & 208.77 & 23.88 \\
\hline $60-66$ & 971.76 & 680 & 1150 & 231.73 & 23.85 \\
\hline $67-71$ & 949.43 & 700 & 1180 & 221.89 & 23.37 \\
\hline $72-77$ & 955.71 & 780 & 1190 & 231.98 & 24.27 \\
\hline $78-84$ & 899.19 & 710 & 1032 & 208.61 & 23.20 \\
\hline $85-91$ & 899.00 & 637 & 1110 & 204.98 & 21.98 \\
\hline $92-98$ & 935.98 & 689 & 1150 & 216.34 & 22.96 \\
\hline 99-104 & 890.87 & 700 & 1027 & 209.75 & 23.50 \\
\hline 105-111 & 970.33 & 719 & 1190 & 256.98 & 20.99 \\
\hline $112-118$ & 928.05 & 690 & 1074 & 224.87 & 24.23 \\
\hline $125-131$ & 986.67 & 723 & 1200 & 241.94 & 24.52 \\
\hline $132-5$ & 948.38 & 730 & 1190 & 230.28 & 24.28 \\
\hline
\end{tabular}

TABLE 4: Measurements of cross-cut for external and internal shell.

\begin{tabular}{lccc}
\hline \multicolumn{1}{c}{ External shell } & & \multicolumn{2}{c}{ Internal shell } \\
Relevance paintings & Category & Relevance paintings & Category \\
\hline 1 & 0 & 1 & 1 \\
2 & 1 & 2 & 0 \\
3 & 0 & 3 & 0 \\
4 & 0 & 4 & 0 \\
5 & 1 & 5 & 1 \\
6 & 1 & 6 & 0 \\
\hline
\end{tabular}

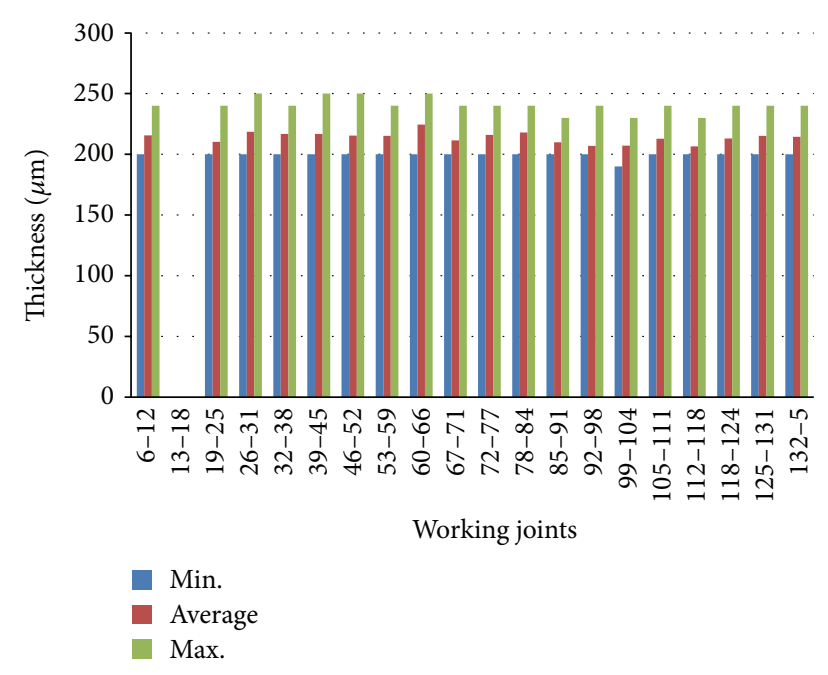

FIGURE 10: Overall thickness paintings external shell.
Figure 12 shows the total coating thickness of organic coatings on the inside surface of the cooling tower. On the inside surface of the cooling tower two cases were presented (Table 6):

(i) under the ring of the cooling tower where the thickness of the coatings had to be $300 \mu \mathrm{m}$ epoxy paint,

(ii) above the ring of the cooling tower where the thickness of the coatings had to be $450 \mu \mathrm{m}$ ( $300 \mu \mathrm{m}$ epoxy paint and $150 \mu \mathrm{m}$ polyurethane).

Figure 12 indicates that the average is $400 \mu \mathrm{m}$. Even the minimum values of measurements are over $350 \mu \mathrm{m}$.

Figure 13 shows the total coating standard deviation\% and the standard deviation of organic coatings on the inside surface of the cooling tower. The average of standard deviation\% was 10.59. Analytical measurements of Figures 12 and 13 are presented in Table 4. 
TABLE 5: Total thickness of organic coatings $(\mu \mathrm{m})$ on the concrete surface external shell under the ring.

\begin{tabular}{|c|c|c|c|c|c|}
\hline \multicolumn{6}{|c|}{ Overall thickness paintings external shell } \\
\hline Working joints & Average & Min. & Max. & $\begin{array}{l}\text { Standard deviation } \\
\text { (SD) }\end{array}$ & $\begin{array}{c}\text { Standard deviation (SD) } \\
(\%)\end{array}$ \\
\hline $6-12$ & 215.71 & 200 & 240 & 12.49 & 5.79 \\
\hline $13-18$ & 0 & 0 & 0 & 0 & 0 \\
\hline $19-25$ & 210.29 & 200 & 240 & 10.82 & 5.15 \\
\hline $26-31$ & 218.57 & 200 & 250 & 17.91 & 8.19 \\
\hline $32-38$ & 216.86 & 200 & 240 & 13.68 & 6.31 \\
\hline $39-45$ & 216.86 & 200 & 250 & 14.10 & 6.50 \\
\hline $46-52$ & 215.43 & 200 & 250 & 13.80 & 6.41 \\
\hline $53-59$ & 215.14 & 200 & 240 & 12.96 & 6.02 \\
\hline $60-66$ & 224.57 & 200 & 250 & 17.29 & 7.70 \\
\hline $67-71$ & 211.43 & 200 & 240 & 10.18 & 4.82 \\
\hline $72-77$ & 216.00 & 200 & 240 & 10.47 & 4.85 \\
\hline $78-84$ & 218.00 & 200 & 240 & 13.05 & 5.99 \\
\hline $85-91$ & 210.00 & 200 & 230 & 10.00 & 6.00 \\
\hline $92-98$ & 206.90 & 200 & 240 & 8.35 & 4.03 \\
\hline 99-104 & 207.24 & 190 & 230 & 8.67 & 4.18 \\
\hline 105-111 & 212.86 & 200 & 240 & 12.55 & 5.90 \\
\hline $112-118$ & 206.55 & 200 & 230 & 7.55 & 3.66 \\
\hline $118-124$ & 213.14 & 200 & 240 & 12.14 & 5.69 \\
\hline 125-131 & 215.14 & 200 & 240 & 11.31 & 5.26 \\
\hline $132-5$ & 214.48 & 200 & 240 & 12.20 & 5.69 \\
\hline
\end{tabular}

TABLE 6: Organic coating total thickness $(\mu \mathrm{m})$ on the surface concrete of internal shell (above the ring).

\begin{tabular}{|c|c|c|c|c|c|}
\hline \multicolumn{6}{|c|}{ Overall thickness paintings internal shell } \\
\hline Working joints & Average & Min. & Max. & $\begin{array}{l}\text { Standard deviation } \\
\text { (SD) }\end{array}$ & $\begin{array}{c}\text { Standard deviation (SD) } \\
(\%)\end{array}$ \\
\hline $6-12$ & 398.33 & 300 & 500 & 80.709 & 20.26 \\
\hline $13-18$ & 490.83 & 480 & 510 & 10.961 & 2.23 \\
\hline $19-25$ & 480.00 & 450 & 520 & 22.361 & 4.66 \\
\hline $26-31$ & 390.56 & 300 & 480 & 72.147 & 18.47 \\
\hline $32-38$ & 440.42 & 310 & 540 & 80.324 & 18.24 \\
\hline $39-45$ & 527.22 & 500 & 580 & 25.507 & 4.84 \\
\hline $46-52$ & 387.22 & 300 & 490 & 72.786 & 18.80 \\
\hline $53-59$ & 478.33 & 460 & 500 & 16.750 & 3.50 \\
\hline $60-66$ & 461.67 & 340 & 510 & 60.702 & 13.15 \\
\hline $67-71$ & 403.33 & 300 & 490 & 71.880 & 17.82 \\
\hline $72-77$ & 480.00 & 440 & 530 & 22.870 & 4.97 \\
\hline $78-84$ & 470.00 & 450 & 520 & 23.805 & 5.06 \\
\hline $85-91$ & 481.11 & 450 & 510 & 18.526 & 3.85 \\
\hline $92-98$ & 401.11 & 300 & 485 & 72.102 & 17.98 \\
\hline $99-104$ & 498.33 & 480 & 520 & 12.134 & 2.43 \\
\hline 105-111 & 387.06 & 300 & 480 & 80.130 & 20.70 \\
\hline $112-118$ & 475.00 & 450 & 500 & 17.078 & 3.60 \\
\hline $125-131$ & 418.00 & 300 & 490 & 73.230 & 17.52 \\
\hline $132-5$ & 477.78 & 450 & 510 & 15.476 & 3.24 \\
\hline
\end{tabular}




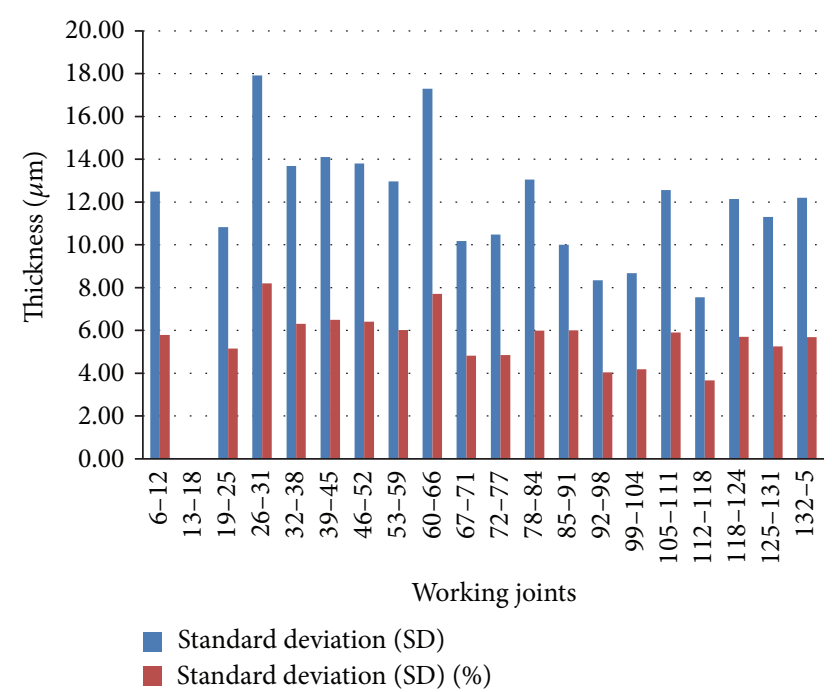

FIGURE 11: Standard deviation of acrylic emulsion coating on the surface of external shell.

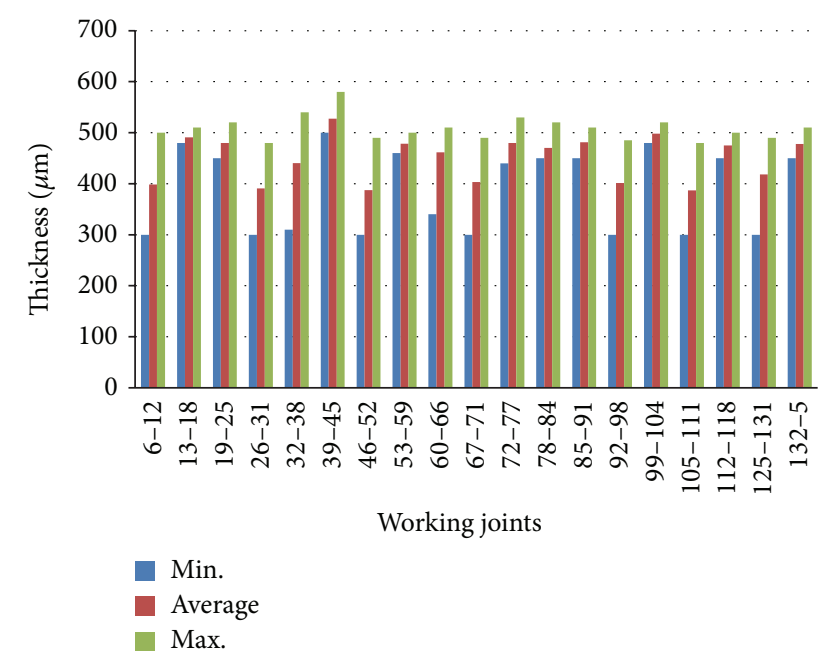

FIGURE 12: Total thickness of organic coatings $(\mu \mathrm{m})$ on the surface of concrete internal shell (above the ring).

Adhesion tests of organic coatings were also made using the pull-off method. These tests generally agree with the method cross-cut. In general, the adhesion of coatings on both arms and concrete was satisfactory despite the difficulties. The most difficult part of applying the coating was the weather, because of the intense humidity that existed in the atmosphere.

After one year of operation, the cooling tower was shut down for three days to allow for the necessary maintenance works. Because of short time, it was not possible for measurements to be taken. During this time, an optical inspection of the internal tower was made, which showed good behavior of coatings. The reinforcements, which did not have mortar concrete, showed no general corrosion. As is evident from Figure 11 (inner part), the state of epoxy coating is generally good and delamination and bubbles were not observed.

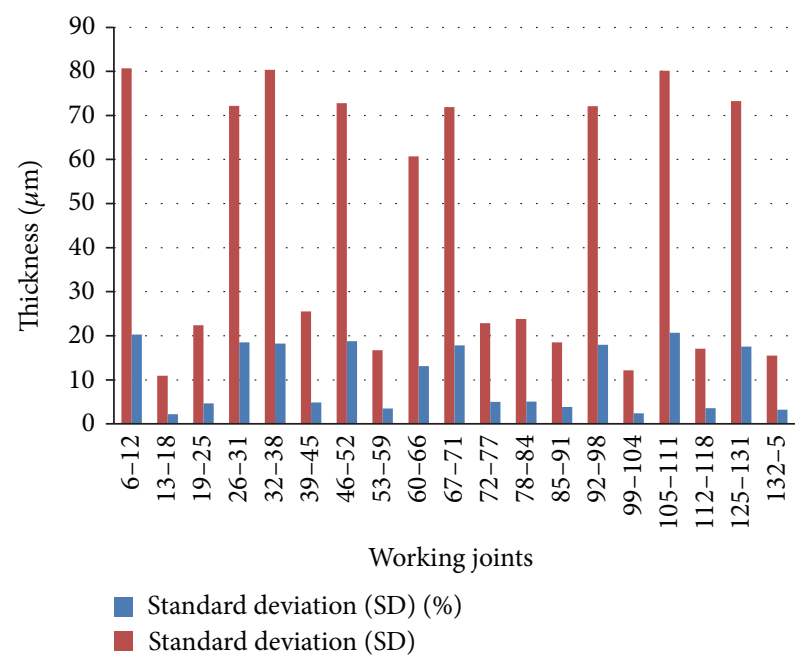

FIGURE 13: Overall standard deviation of paintings of internal shell (above the ring).

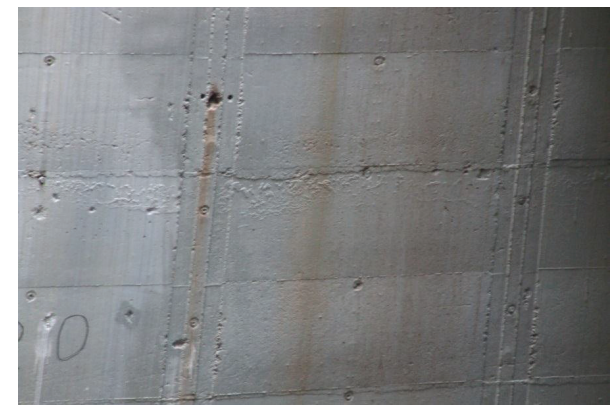

FIGURE 14: After a year of use of the cooling tower.

FIGURE 15: Classification of the cross-cut test (standard ISO 2409: $1992(\mathrm{E}))$.

The repair of concrete showed no problems. Red spots are corrosion products from the oxidation of protruding steels. This protruding steel is not reinforcement and exists only for the initial works. The protruding bars are covered only with epoxy primer.

Figure 14 shows that reinforcing bars, which protrude outward, are not part of the structure but simply exist only for supporting reasons.

\section{Conclusions}

The measurements of this study showed the following.

(i) The coverage of reinforcement with coating of cementations coating presented large fluctuations and the average of the measurements did not reach $1000 \mu \mathrm{m}$. 
(ii) The coverage of concrete with organic coatings, both internally and externally, reaches and exceeds the required limits.

(iii) The relevance of the coating with the substrate (reinforcement and concrete) was very good.

(iv) The average of the total thickness of coating on the outer shell is stable in all working joints but there was a great standard deviation.

(v) There was a greater standard deviation within the internal shell than in the outer shell. This is because there were more layers of painting inside (epoxy, polyurethane).

\section{References}

[1] L. Etchevery, "The rehabilitation of cooling towers," in Proceedings of the Concrete International, pp. 1-4, January 2005.

[2] R. Engelfried, "Natural draught cooling towers," in Proceedings of the 4th International Symposium on Natural Draught Cooling Towers, pp. 199-206, Kaiserlauten, Germany, 1996.

[3] R. Engelfried and D. Busch, "Condition of internal coatings of cooling towers as a consequence of FGD operating loads and of environmental impacts," VGB PowerTech, vol. 76, no. 1, pp. 65-70, 1996.

[4] R. Engelfried, "State-of-art of concrete refurbishment measures within Europe, especially in Germany," in Proceedings of the International Concrete Repair Institute Annual Meeting, New Oerleans, La, USA, 1996.

[5] R. Engelfried, "Beherrschung der Schichtdickenproblematic bei Beschichtungen dyrch Stoffhersteller, Planer und Ausfuerungsunternehmer," in Proceedings of the 4th International Colloquium Materials, Science and Restoration, vol. 1, pp. 347-352, Technishe Akademie Esslingen, 1996.

[6] G. Batis, N. Kouloumbi, and P. Pantazopoulou, "Corrosion protection of steel in pumice lightweight mortar by coatings," Cement and Concrete Composites, vol. 27, no. 2, pp. 261-267, 2005.

[7] G. Batis and E. Rakanta, "Corrosion of steel reinforcement due to atmospheric pollution," Cement and Concrete Composites, vol. 27, no. 2, pp. 269-275, 2005.

[8] VGB Power Tech, Guideline: Protection Measures on Reinforced Concrete Cooling Towers and Chimneys against Operational and Environmental Impacts, VGB Power Tech, Essen, Germany, 3rd edition, 2010.

[9] "DIN 50986 measurement of coating thickness, wedge cut method for measuring the thickness of paints and related coatings," Tech. Rep., 1979.

[10] EN ISO 2409N, "Paints and varnishes-cross-cut test," Tech. Rep. 2007-08-01, 2007. 

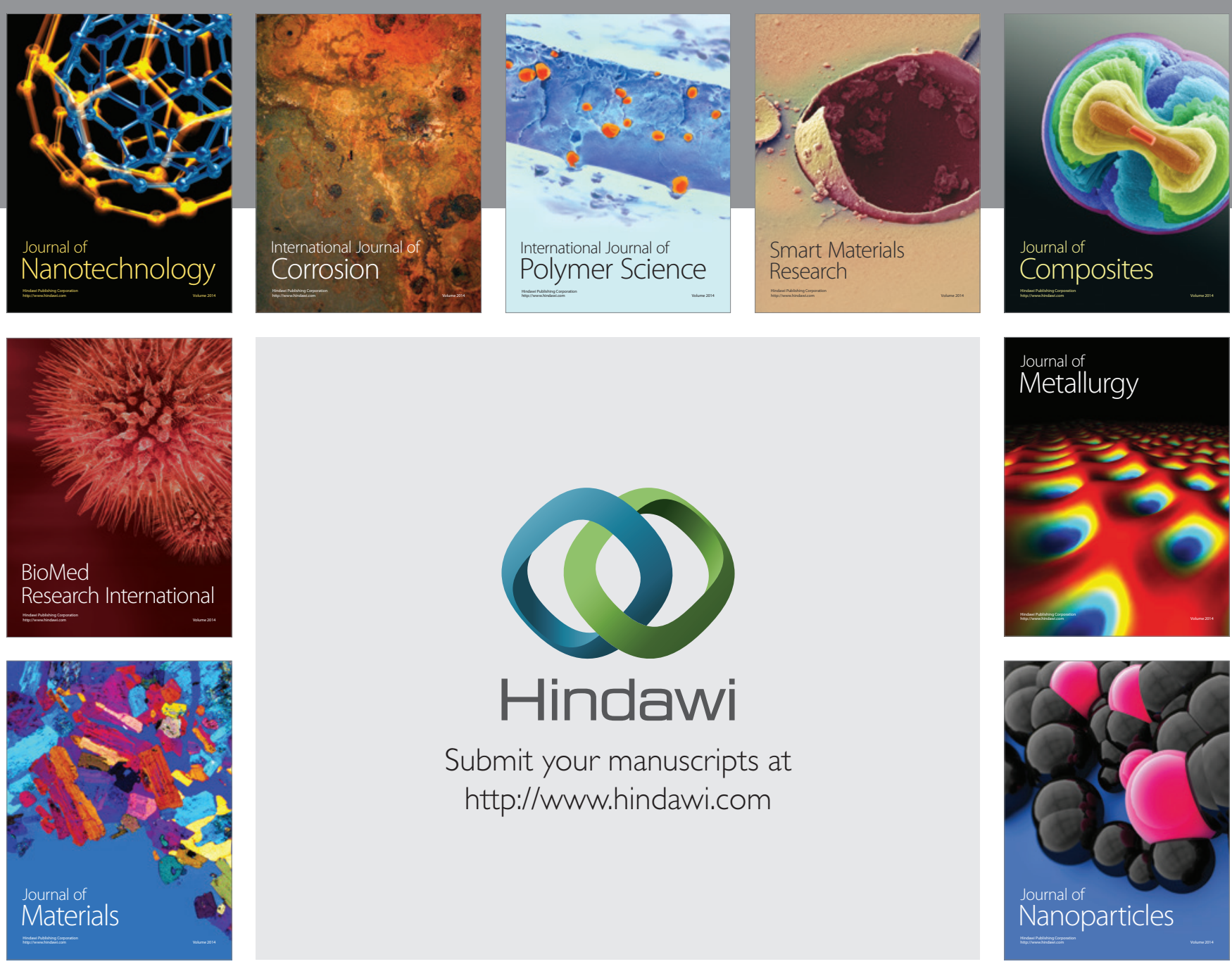

Submit your manuscripts at http://www.hindawi.com
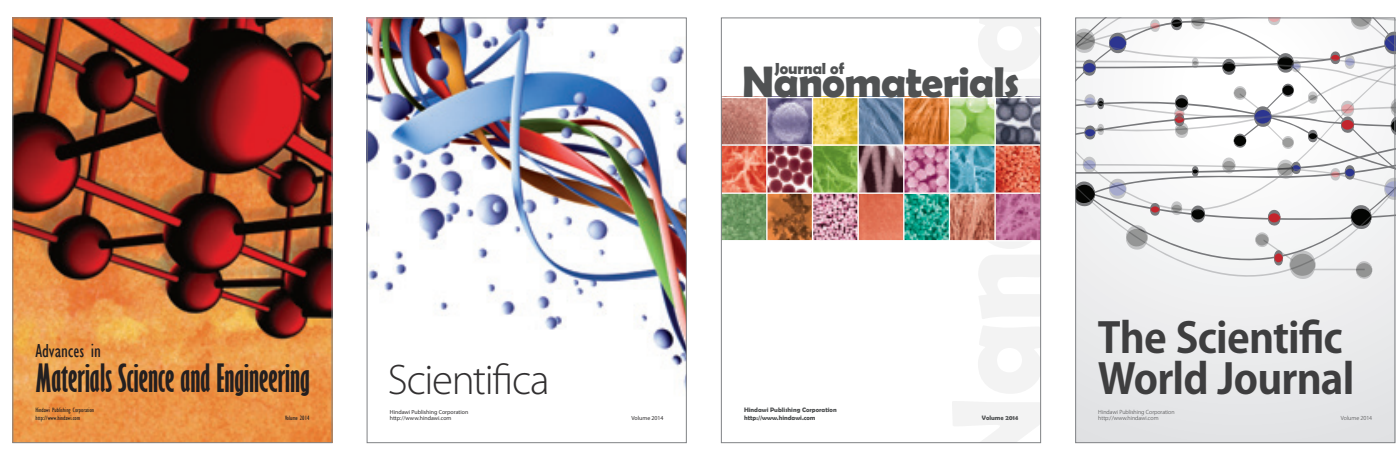

\section{The Scientific World Journal}
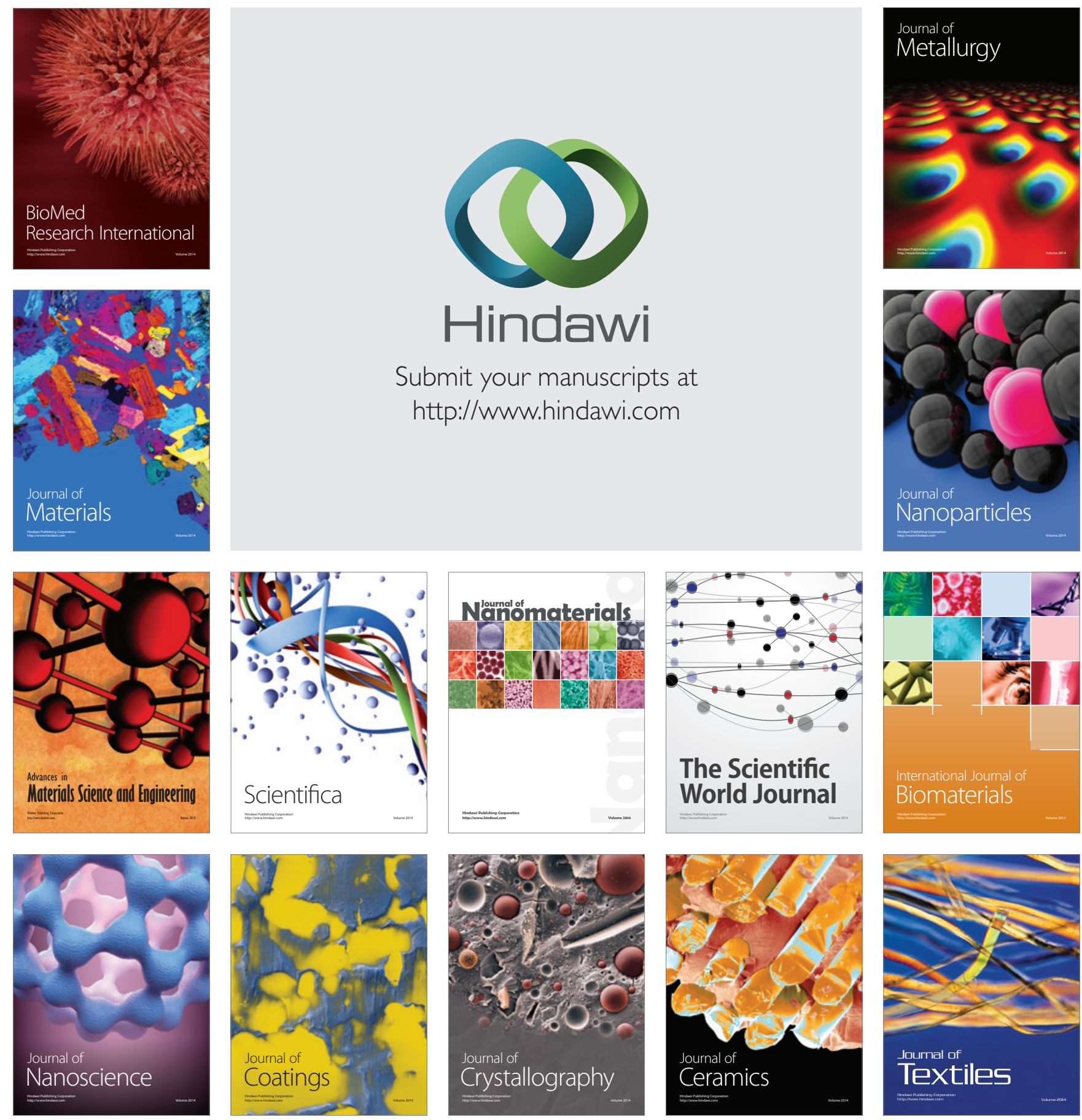